\title{
Intelligent Multi-Agent Technologies for Activating Security at Kwara State Polytechnic, Ilorin
}

\section{Raji Ayodele Kamaldeen, Abdulrahman Tosho Abdullahi, Abdulkareem Quadri Bolaji, Saka Tajudeen Olarenwaju}

Department of Computer Science, Kwara State Polytechnic, Ilorin, Nigeria

\section{Email address:}

kamalayo2004@yahoo.com (A. K. Raji),Toshman3k@gmail.com (T. A. Abdulrahman), quadribolajiabdulkareem@gmail.com (Q. B. Abdulkareem), sakataju70@yahoo.com (T. O. Saka)

\section{To cite this article:}

Raji Ayodele Kamaldeen, Abdulrahman Tosho Abdullahi, Abdulkareem Quadri Bolaji, Saka Tajudeen Olarenwaju. Intelligent Multi-Agent Technologies for Activating Security at Kwara State Polytechnic, Ilorin. International Journal of Industrial and Manufacturing Systems Engineering. Vol. 2, No. 4, 2017, pp. 34-41. doi: 10.11648/j.ijimse.20170204.11

Received: July 30, 2017; Accepted: August 25, 2017; Published: October 3, 2017

\begin{abstract}
Advancement in development of Information and Communication Technology engendered by the invention of agent technologies have fundamentally altered the ways the environment is secured. The advent of Intelligent Multi Agent technologies has also brought changes to various human activities, notably in respect of security. A multi-agent system (MAS) is a system composed of multiple interacting intelligent agents. Multi-agent systems can be used to solve problems which are difficult or impossible for an individual agent or monolithic system to solve like effective and continuous monitoring of the environment. It is observed that most institutions such as polytechnics and universities campuses are in critical positions with respect to securing of capital assets (i.e. detecting any problem through monitoring: temperature, motion, etc). Sensor networks are among the most important tools for performing such tasks. In this research work, multi agent technologies system was used to secure and/or monitor the buildings and rooms of a Polytechnic campus. The system is based on Intelligent multi agents and Wireless LAN connected sensors using JADE (Java Agent Development Environment), Netbeans and Java Development Kit (JDK).
\end{abstract}

Keywords: Security Systems, Intelligent Multi-Agent, Sensor, Wireless LAN, Securing

\section{Introduction}

Security and Automation is a primary issue in a modern domestic and office environment. The use of wireless sensor network in automation offers various advantages and new challenges. Most institutions such as Polytechnics and Universities campuses are in critical positions with respect to securing of capital assets (i.e. detecting any problem through monitoring: temperature, motion, etc). Sensor networks are among the most important tools for performing such tasks [1]. The advent of Intelligent Multi Agent technologies has brought changes to various human activities, notably in respect of security. This is because agent-based technology has the capability to distribute intelligence throughout the network and dynamically perform security management functions [2]. A multi-agent system (MAS) is a system composed of multiply interacting agents. Intelligent is a general term to describe some of mind activities such as logical thinking, judging, planning and learning [3] [4]. Artificial Intelligence (AI) is the study of how machines could be programmed to emulate intelligent behaviours especially that of human [5]. It also attempts to bring computers a little closer to human brain's capabilities by imitating certain aspects of information processing in the brain, in a highly simplified way. An agent is anything that can perceive its environment through sensors and acting upon that environment through effectors [4].

However, securing a Polytechnic campus could be achieved based upon a number of security guards making security checking rounds (on foot or by vehicles) inside the polytechnic campus. Other way is to use security camerabased systems [1]. Nonetheless, such systems need to be monitored on the fly by a person and the attacker otherwise may be wearing a mask or dressed as a security guard which makes it unreliable. Hence large environment cannot be monitored and secured by human efforts alone. This could be overcome by the use of intelligent multi-agent software. The 
system has advantage over human based and camera-based systems. This paper presents the Design and Implementation of Intelligent Multi Agent Technologies for Activating Security at Kwara State Polytechnic, Ilorin.

\section{Aim and Objectives}

The research work was aimed to determine the state of the existing Information Technology (IT) in the Polytechnic and to justify needs for intelligent multi agent technologies. The main objective was to design such technologies, with a view of activating security of assets in the Polytechnic. Other objectives include;

i. to create system that would provide adequate monitoring for critical facilities.

ii. to create a system that would enable fast threat notification to security operatives in other to respond to the threat as fast as possible.

\section{Related Works}

Reference [1] assumes that most of organizations such as Universities campus have critical positions and rooms and therefore require to be secured. "Securing" here is detecting any problem through monitoring: temperature, motion, etc. Securing a University campus could be achieved based upon a number of security guards making security checking rounds (on foot or by vehicles) inside the university campus. Other way is to use security camera-based systems. Nonetheless, such systems need to be monitored on the fly by a person and the attacker otherwise may be wearing a mask or dressed as a security guard which makes it unreliable. The agent can sense and act on its environment, and has a set of goals or motivations that it tries to achieve through these actions. Multi agent systems can be used to solve problems which are difficult or impossible for an individual agent or monolithic system to solve [2].

According to [3], telecommunication networks have become an inseparable technology; however there is a noticeable lack of powerful and dynamic management tools for resource configuration mainly due to rapid increase in transmission speeds and increasing number of users and services. Senor-based systems could be also used to automatically notify emergency centres of a given problem. They are commonly equipped with distributed sensors and used to collect incident severity information. The system then communicates with an emergency dispatcher to assist in determining the appropriate emergency personnel [11].

Multi-agent systems (MAS) have grown and are applied to various fields such as simulation and artificial life, robotics, image processing in the last few decades. MASs are integrated into the security, because of their intelligence and adaptation to the field. DMWSNs [13] proposed Distributed Monitoring for WSNs using multi-agent approach where the main goal is the conception of software architecture and the network organization dedicated to optimization, performance analysis, and monitoring as well as topology control. The main objective is to have a fault-tolerant network and extend its lifetime by optimizing the choice of paths based on changing parent method. The new concept of degree of tolerance was used in the choosing parent and/or neighbour procedure. Castalia simulator which is based on the simulator Omnet++ was used to implement the approach.

MFTS [14] proposed a novel multi-agent fault tolerant system for wireless sensor networks. Multi-agent and mobile agent configuration was used to reduce energy consumption and also to manage WSNs that provide energy-efficient services. The multi-agent system consists of a resource manager, a fault tolerance manager and a load balancing manager, and we also propose fault-tolerant protocols that use multi-agent and mobile agent setups. Java was used to conduct the simulation.

IWSNM-MAS [15] proposed Intelligent Wireless Sensor Network Management based on a Multi-Agent System. Mobile agent was used to collect data according to a routing scheme for sensor networks based on clustering technique. Nodes were assigned as the processing function instead of the sink. At each node of the network an agent was introduced to process data locally with the possibility of removing any redundant data. The nodes were clustered together with a clustered head using Local Closest First (LCF) algorithm to determine a scheme for the nodes belonging to the same group. Simulations were performed using $\mathrm{C}++$ Builder and the result shows extension of the lifetime of the network in terms of energy consumption and the rate of packet delivery.

\section{Research Methodology}

\subsection{Design Methodology}

Four-step methodology was proposed for building a multiagent application. The methodology focuses on logical issues of the problem being considered and then converges to the implementation. The stages are:

Identifying the Agents: Starting with the list of aims we want the system to satisfy, then considering various entities that will be interacting with each other to achieve this global aim. These entities represent the agents in the system. After identifying the agents, clarify the aims of each agent and the service they provide. The agents are divided into different categories by grouping the agents with similar aims and services into a single category. These categories help in identifying the agent classes in the application. After identifying the agent classes, then identify the application specific classes that each agent class may use.

Identifying the Conversations: When developing agents, the world is being viewed as composing of intelligent things. At this stage, we begin to model the interaction between these things in the form of conversations. Identify every possible conversation an agent can engage in, and represent those conversations by developing an automata model for each of them. These different automata models identify the different conversation classes in the application. 
Identifying the Conversation Rules: Each conversation is represented by an automata model. Alternative action of an agent produce different states in the conversation (automation) and the current state of a conversation influences how the agent react in the next moment. Conversations are rule-based descriptions of what agent does in certain situations.

Analyzing the Conversation Model: It is important to do an analysis of the logical consistency of all agent conversation in order to design multi-agent system that finds a coherent solution to the entire system problem. They should be analyzed to verify the coherency of the system.

\subsection{System Specification}

The main components of the system are:

Wireless sensors and receivers: Wireless sensors will be distributed in critical rooms to detect and to alert the system in case of a security attack occurred.

Database: The database contains information about sensor flags and locations, security guards, critical campus rooms in which there are sensors.

PDAs and/or mobiles: Security guards will be provided with PDAs or mobiles.

Two set of laptops were used to design an integrated system. The laptops were installed and activated with Window 8 Operating System. Other software that were installed are:

Java Development Kits (JDK) with Java Runtime Environment

Java Agent Development Environment (JADE) Library and Binaries

Net Bean IDE 8 with MYSQL Database Server Engine
Factory Agent Programming Language 2 (AFAPL2) Wamp Server for Local Host Communication

\subsection{Program Design and Development}

The system was constructed to incorporate Java Agent Development Environment (JADE) Library [8] and Binaries, Net Bean IDE 8 with MYSQL Database Server Engine and Factory Agent Programming Language 2 (AFAPL2). In such a way, nearby security guards shall be located instantly. System design deals with the coordination of activities, procedures and the utilization of equipment in order to achieve the research objectives. In any system design, the output is considered first because it is the desired output that will determine both the input and the procedure.

The design of the system comprises of the following design phase:

(a). Output design

(b). Input Design

(c). Database Design

(d). Procedure Design

This system was designed in JAVA using JADE platform and run on Net Bean Environment.

\section{A. Output Design}

The output is designed to be an interactive screen design and aids future change. It presents information to system users and most visible component of a working system. These outputs are produced from data that is either retrieved from database or, more often, input by users.

Figure 1 below Shows the Security System Agent which is the main agent that must booted up first before any other agent is booted. It is the central agent that handles threat resolving and facility registration as well as identification.

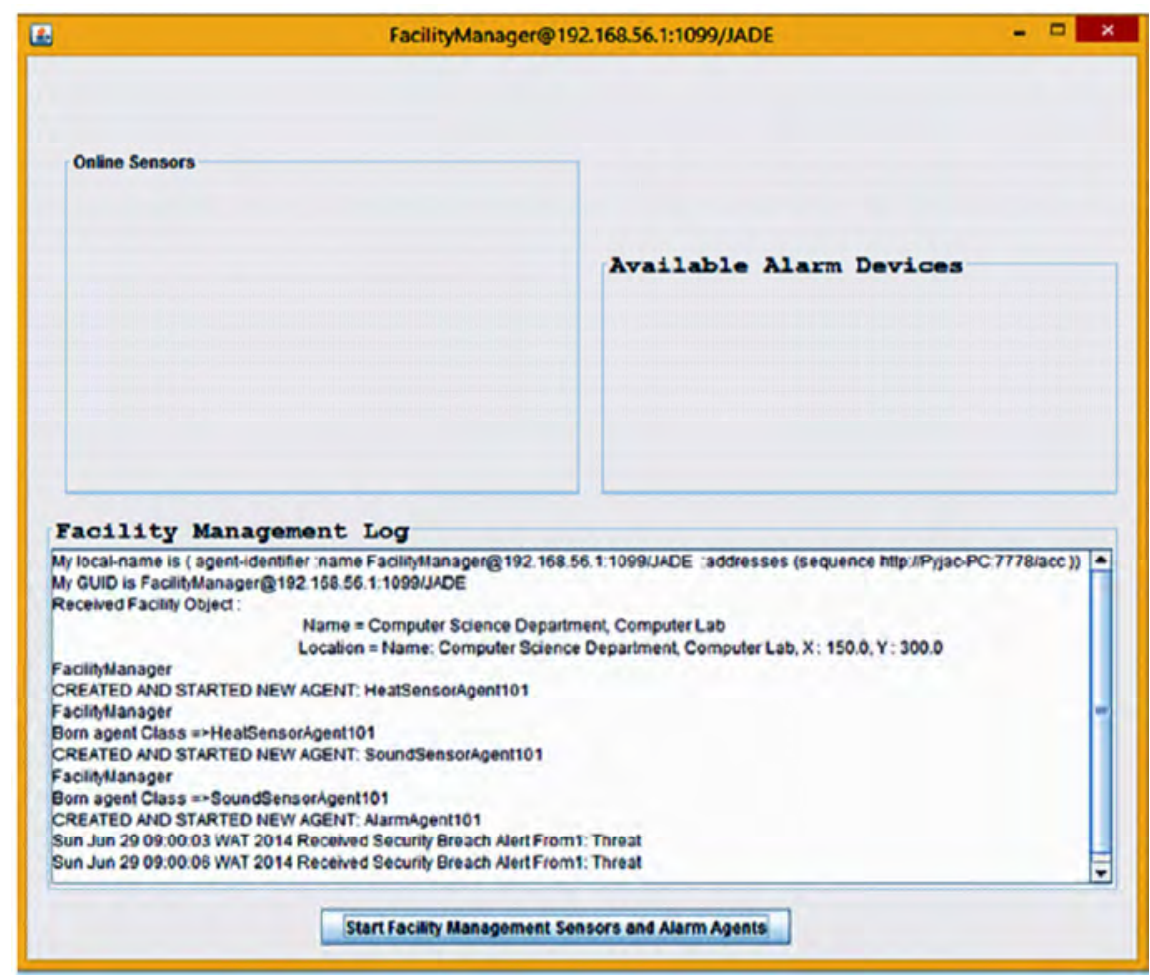

Figure 1. Security System Agent. 
Figure 2 Shows the Security Operative Agent whose primary objective is to get threat notification based on how close it is to the threat area. It main aim is to resolve any threat reported by the security system. Figure 3 shows the
Facility Manager Agent, it houses the sensors and alarm. It reports any threat detected by the sensors to the security system and also triggers the alarm Agent to put $\mathrm{ON}$ or $\mathrm{OFF}$ the Alarm.

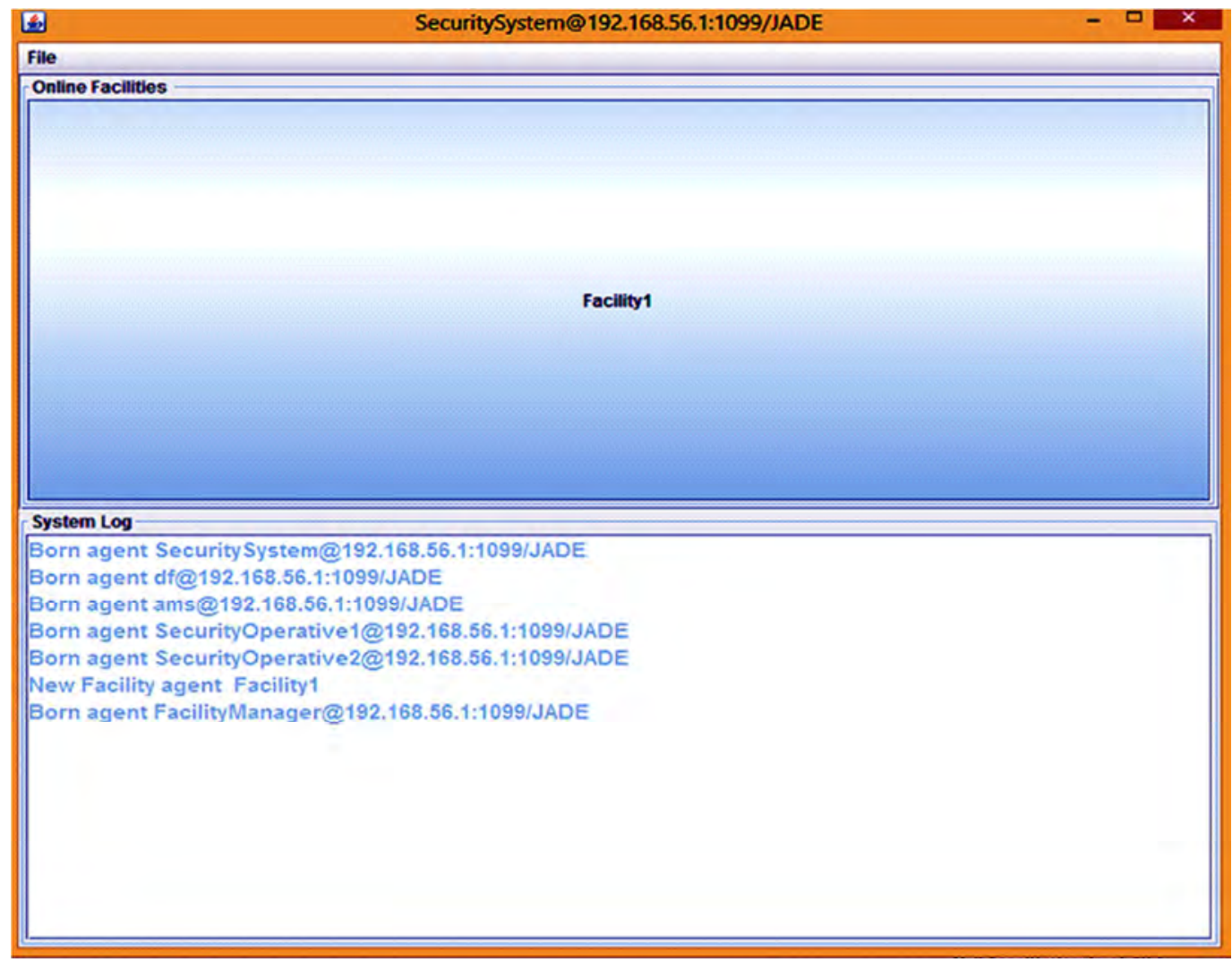

Figure 2. Security Operative Agent.

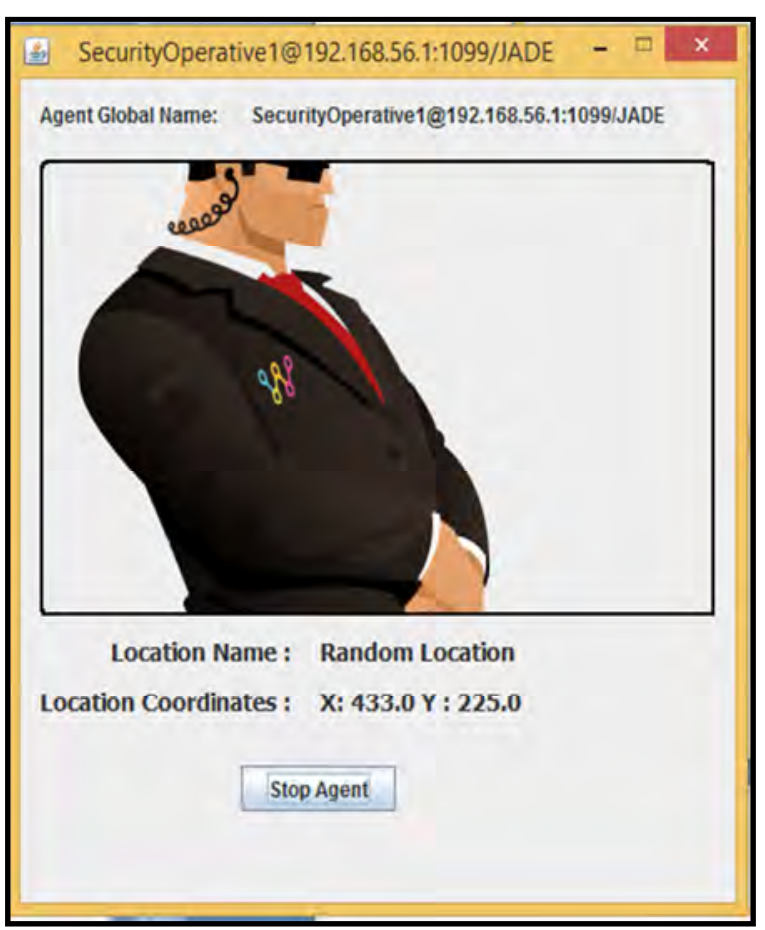

Figure 3. Facility Manager Agent.
Figure 4 shows the Alarm Agent, it is connected to the Facility Manager agent and receives $\mathrm{ON}$ and $\mathrm{OFF}$ trigger from the Facility Manager Agent. It gives an Alarm sound when $\mathrm{ON}$.

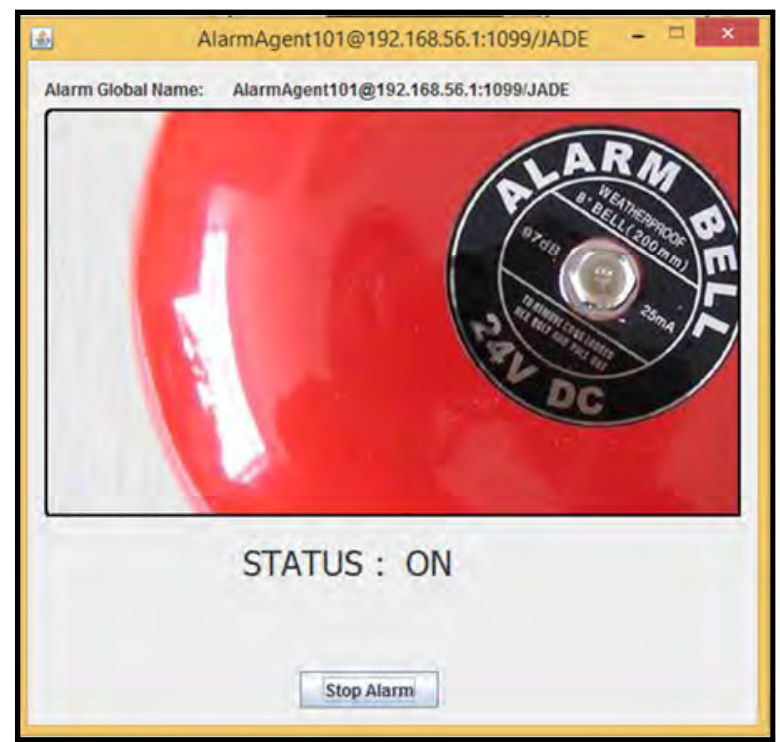

Figure 4. Alarm Agent (Source: Author's Program, 2014). 
Figure 5 shows the Heat Sensor Agent, it stimulates a heat sensor. It notifies the Facility Manager Agent when the stimulated heat level is above normal. Figure 6 shows the Sound Sensor Agent, it stimulates a sound sensor. It notifies the Facility Manager Agent when the stimulated Sound level is above normal.

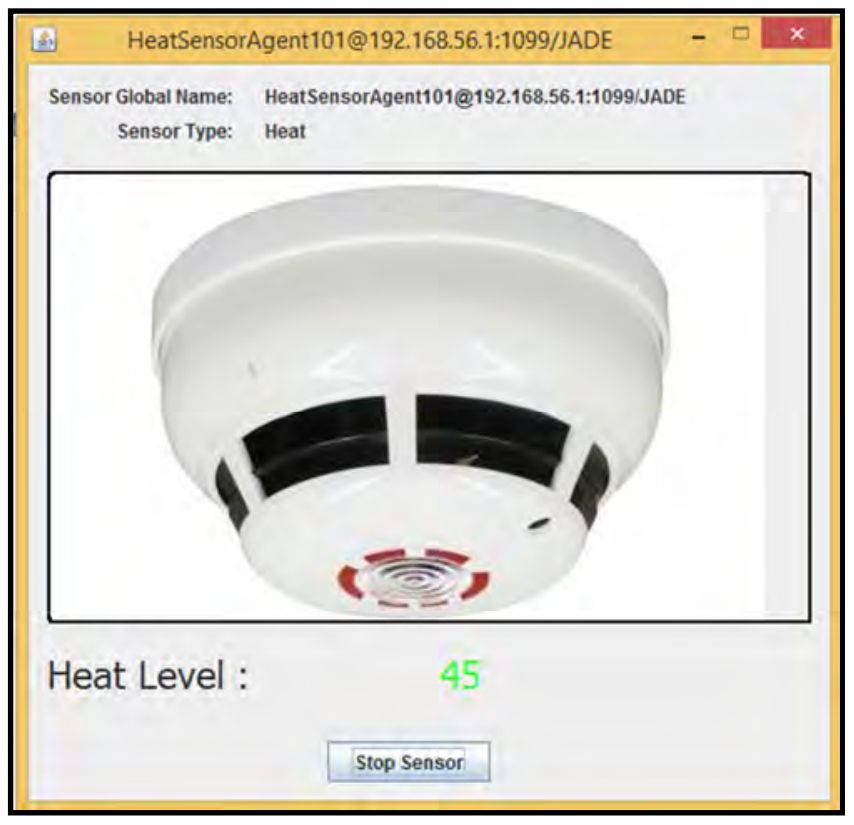

Figure 5. Heat Sensor Agent.

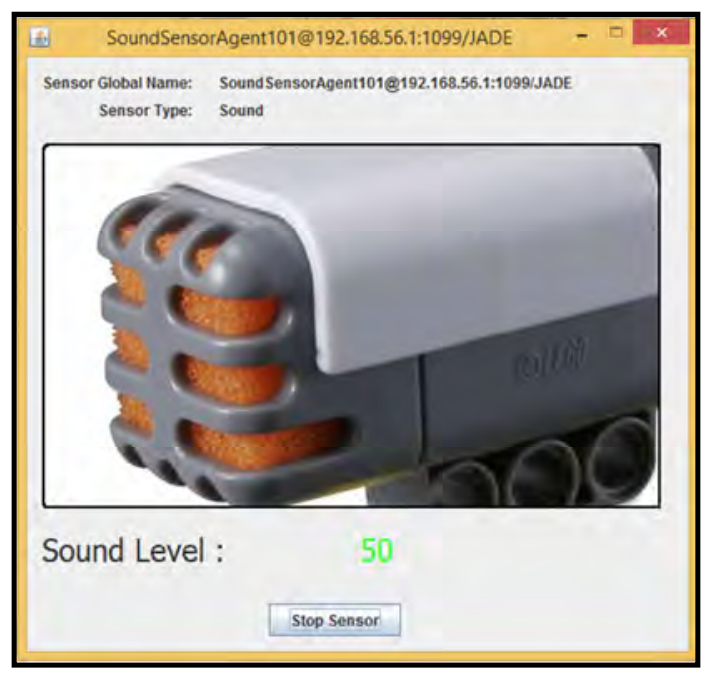

Figure 6. Sound Sensor Agent.

\section{B. Input Design}

Input design involves the selection of the best strategy for getting data into the computer at the right time and as accurately as possible. It facilitates the entry of data into the computer system. Figure 7 shows the Project Properties Dialog, it is used to input the Security System Management Boot Command to the JADE platform on Netbeans. Figure 8 shows the Project Properties Dialog, it is used to input Facility Manager Agent Boot Command to the JADE platform on Netbeans.

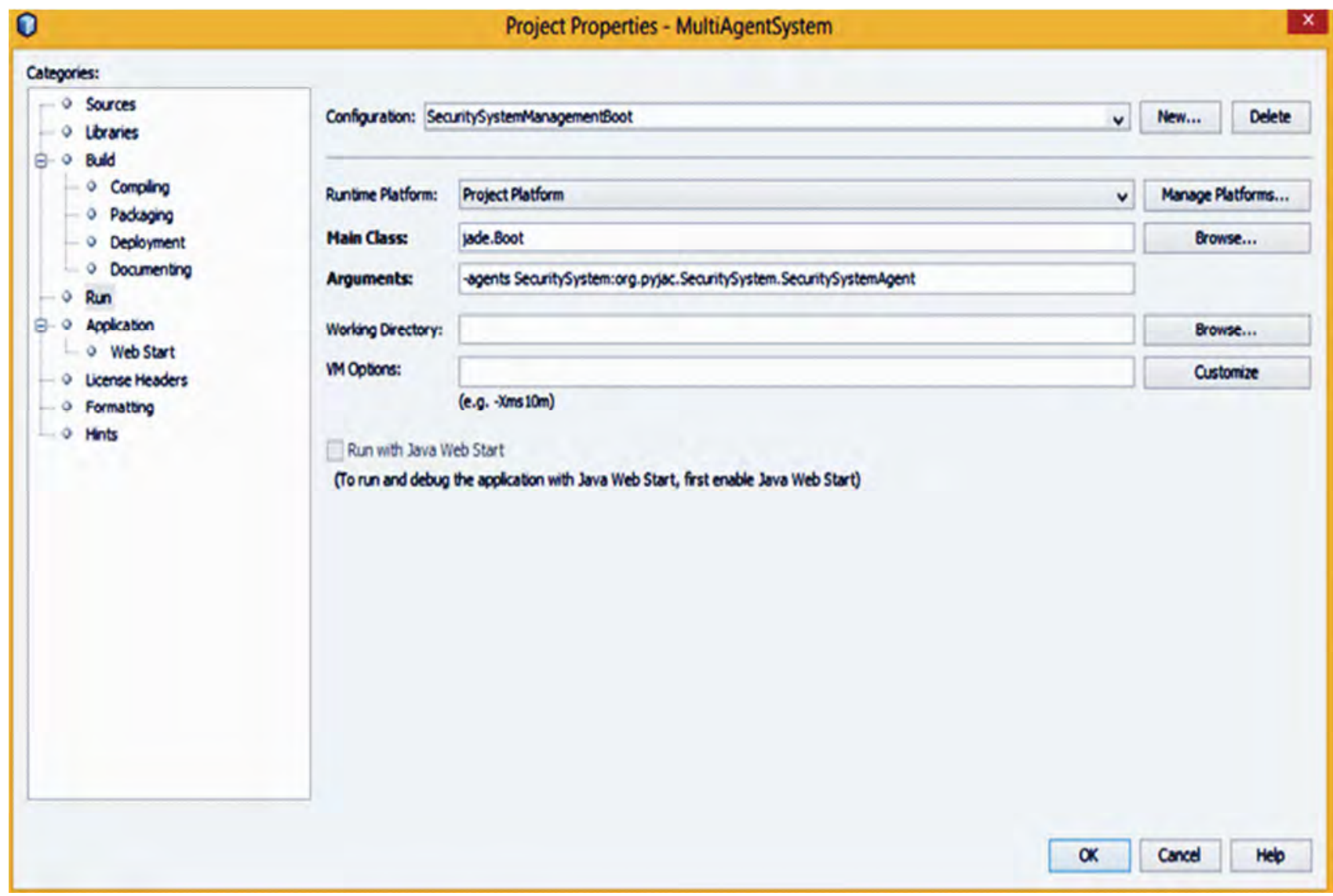

Figure 7. Security System Management Boot 


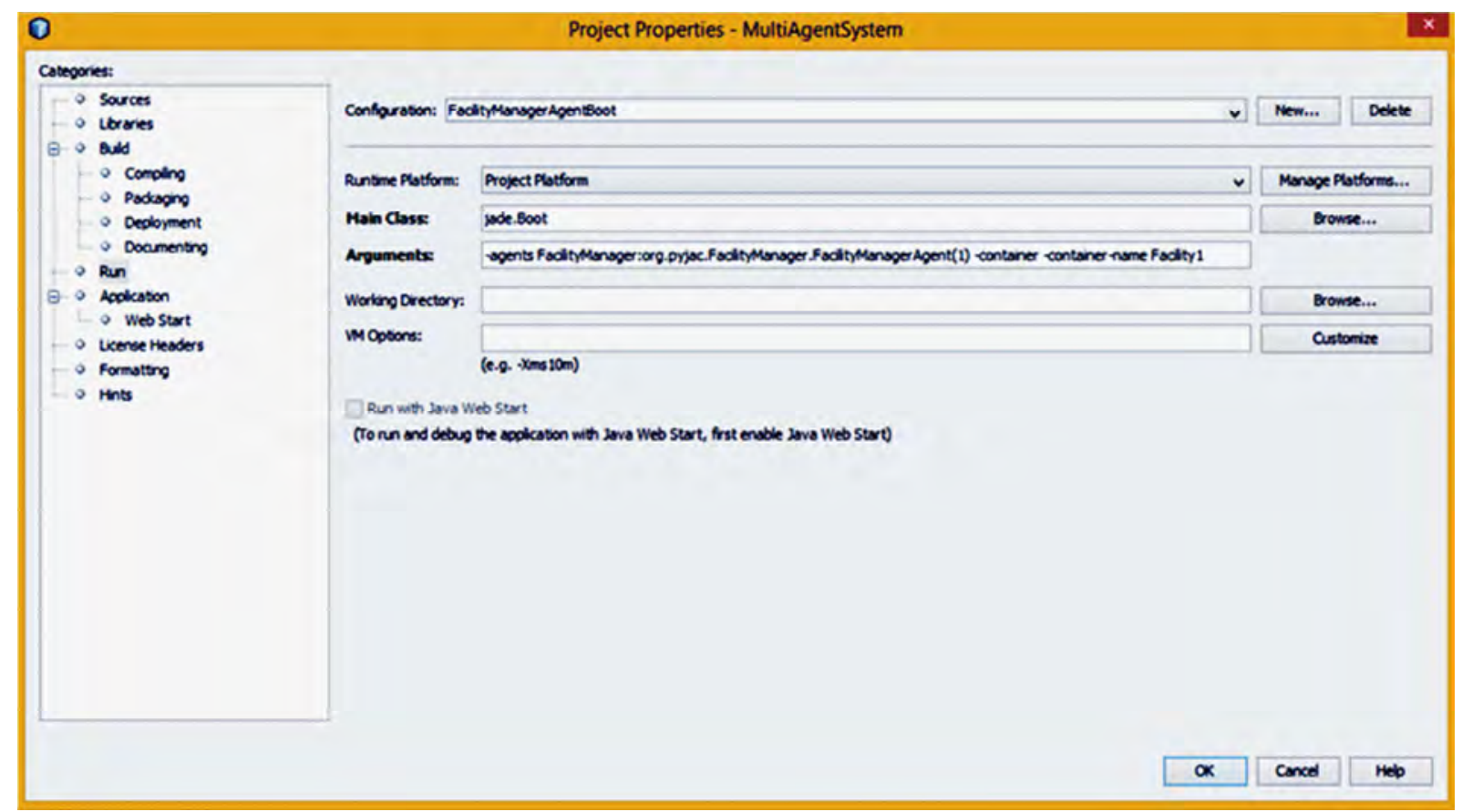

Figure 8. Facility Manager Agent Boot Command.

Figure 9 shows the Project Properties Dialog, it is used to input Security Operative Agent Boot Command to the JADE platform on Netbeans.

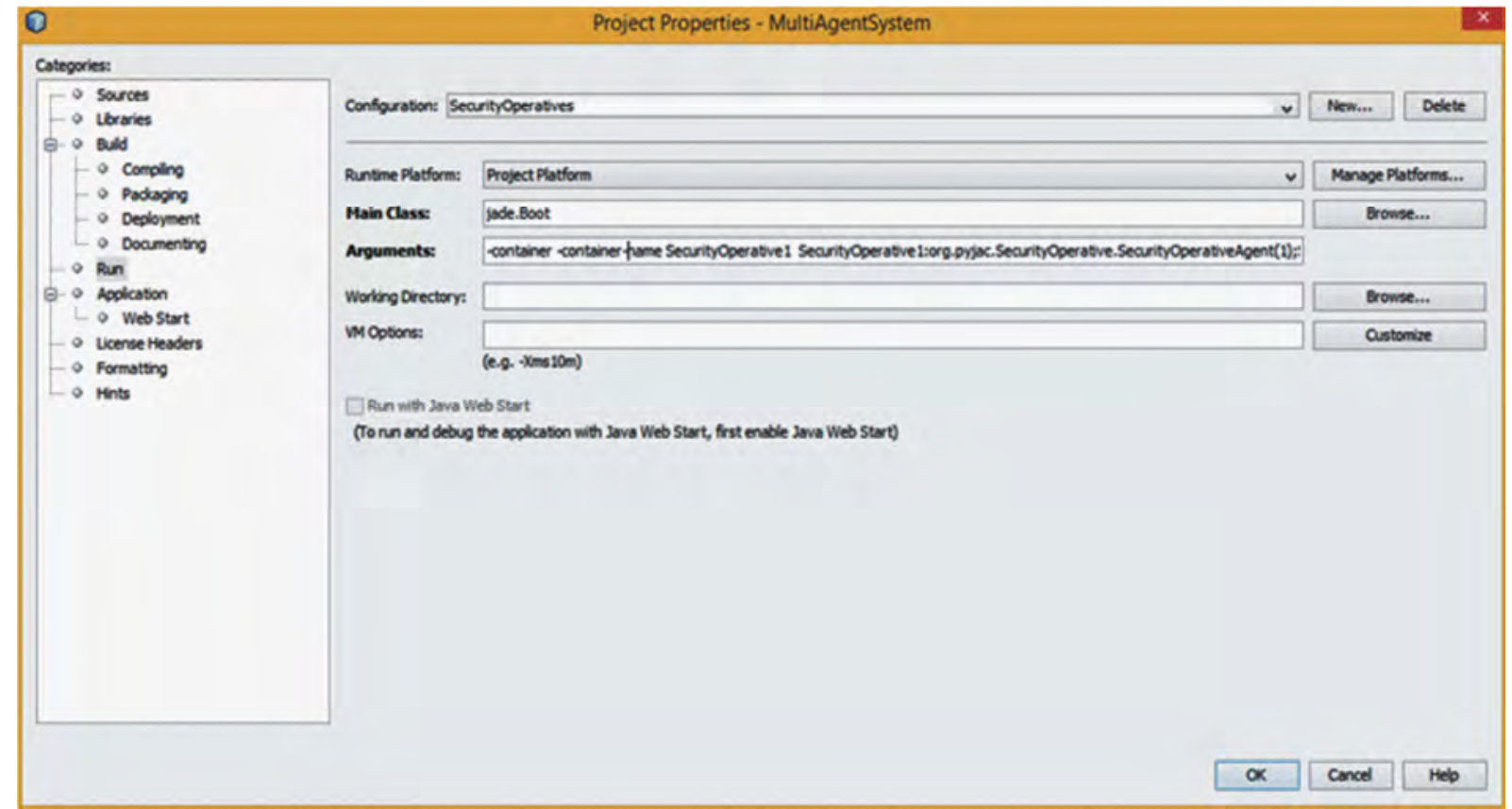

Figure 9. Security Operative Agent Boot Command

\section{Database Design}

The database that was constructed contained the following tables:

a. Attack table: this table is used to make reports on the attacks detected by the sensors and dealt with by the guards during a specified time period.

b. Building table: this table is used to store the buildings name and co-ordinations.

c. Security guard table: this table is used to store the security guards information.

d. Sensors table: It is used to store the sensors information.

e. Sgposition table: This table is used to store the security guards positions.

\section{Procedure Design}

The System was modularized into packages, where each packages houses various classes and methods that collaborate together to form the whole system. All the packages are under the namespace org. pyjac. 
The Security System Package is the most important package in the project because it is the first package to be booted up before any other package is. It boots the Security System Agent which handles Facility Identification/ Registration, Sending of Facility Object to Facility Managers, Receiving of Threat Alert form Facility Managers, Notification of Security Operatives of Threats and Alerting of Facility Managers when Threat issues are resolved.

The Facility Manager Package houses the classes and source files of the Facility Manager Agent. It is booted after the Security System is loaded into the platform. The Facility Manager Agent manages Sensor and Alarm Agents and notifies the Security System Agent when a threat is detected by any of the Sensors in the monitored facility.

The Security Operative package contains needed class files for the Security Operative Agent. The Security Operative Agent listens for threat notification by the Security System Agent and also notifies the Security System Agent when a security threat has been resolved. The Sensor package is the base package for all Sensor Agents in the system. Class and source files of sensors are implemented in the package. The Sensor Agent monitor/observes the attached facility and notifies the Security System Agent when a security threat has been resolved.

The Alarm package includes classes and components of Alarm Agents in the System. The Alarm Agent receives ON and OFF signals from the Facility Manager Agent. The Sound package is where all sound files reside. The Image package contains all the images used by all the packages. The behaviour package contains all the behaviour classes used and shared by all the agents in the system. The ontology package contains classes related to ontology. The DB package contains the database connection classes used to connect to the database.

\section{System Simulation}

Two set of laptops were used for system simulation due to absent of sensor. One of the laptops served as dedicated wireless sensor and the other as dedicated server. Both were equipped with built-in wireless network card (WiFi). Wireless router was used as an access point with fixed IP addresses. The sensor used "JAVA. net. Socket" class to send alarm signal, using TCP to listen to alarm signal (see Figure 10).

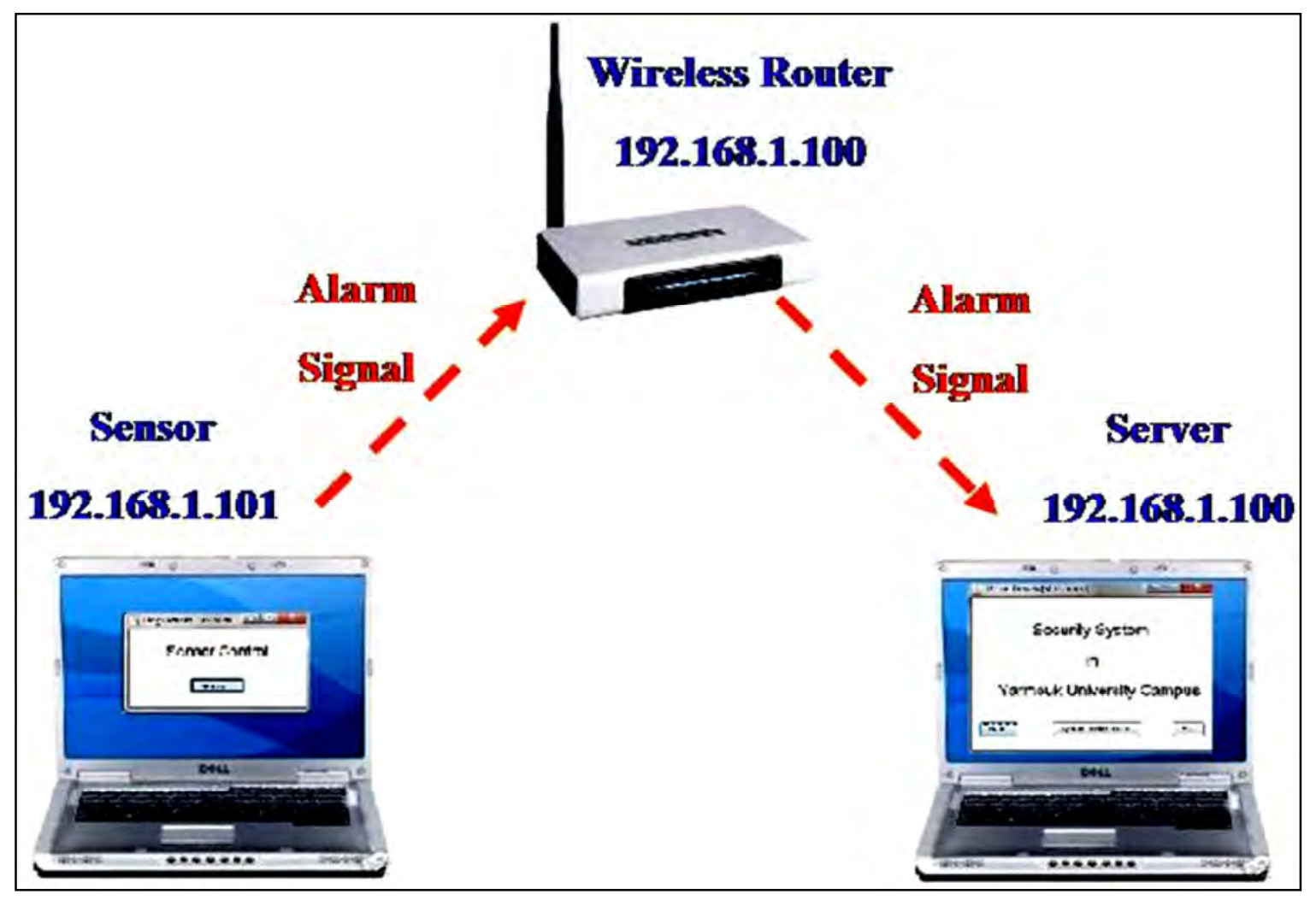

Figure 10. System simulation using laptops.

\section{Discussion of Result}

The system made use of agent technologies to perform the monitoring, reporting and notification of security threats in real time. Sensors are position at critical location in a building to observe the environment for changes in the monitored value which can be heat, noise and motion. The
Sensors, upon detecting a threat, notifies the appropriate facility manager agent to resolve the threat. The facility manger agent turns on the alarm when a threat is reported and also notifies the central security system. Then the Security Guard Call agent receives the information from the Alarm Management Agent and the Building Position Agent and will find the shortest distance between the building in 
which the alarm activated and the location of security guards. The central security system notifies the closest security operative to the scene of the incident reported. The security operative immediately receiving the alert, it is required to visit the scene of the incident to resolve the issue and notify the central security system when the issue has been resolved.

\section{Conclusion}

Intelligent Multi-agent Technologies have been successfully used to design and implement the security system. When an intruder crosses the monitored area, the sensor will detect a change in the intensity of the light since the intruder might obstruct the ambient light conditions in the environment which the sensors are programmed for. When this happens, depending on how much light was interrupted by the intruder, the system will conclude that the light intensity crossed the threshold for triggering the alarm to indicate the presence of an intruder. Consequently, there is no need for a human to continuously monitor the rooms and the buildings of the University campus. Additionally, the system could be used to secure any organization containing critical locations.

Although laptops were used in the implementation to simulate the functions sensors, real sensors could be integrated seamlessly to the system. As a future work, we plan to investigate the usage of cameras in conjunction with this system and therefore use the image processing techniques to extract security attacks features. In this direction, in case of personal attacks, location-based services could be used to track the attacker.

\section{Acknowledgements}

We give thank to Almighty Allah for successful completion of this research. Special gratitude to Tertiary Education Trust Fund (TetFund-Nigeria) for sponsored this research. Thanks also to the Management of Kwara State Polytechnic, Ilorin and all members of staff of Department of Computer Science, Kwara State Polytechnic, Ilorin. Finally, we appreciate the effort and understanding of our family members.

\section{References}

[1] A. Faisal, Z. A. Al-Fakhry, E. Al-Maghayreh, S. Aljawarneh and A. T. Al-Taani, A Multi-Agent-Based System for Securing University Campus. IJRRAS 2 (3), 223-231 March 2010.

[2] H. Luo, Agent based Networks management system. Faculty of graduate studies, University of British: Columbia, 2002.
[3] R. Asadi, N. Mustapha, and N. Sulaiman, A Framework For Intelligent Multi Agent System Based Neural Network Classification Model. International Journal of Computer Science and Information Security (IJCSIS) 5(1), 68-174, 2009.

[4] A. K Raji, Network Monitoring and Management System with Intelligent Multi-agent Technologies, M. Sc Dissertation, Computer Science Department, University of Ilorin, Ilorin, 2012.

[5] S. A Elegbede, M. A Rahman, and A. I Adeleke, Agent System: A Robust Technology for Intelligent Environments. Proceeding of 1 st Conference on Rule of Law and Due Process: A priority for Sustainable Development Developing Nations, Federal Polytechnic, Ede. 1-10 November 2007.

[6] Raji, A. K et al (2013). Developing Digital Library: A Model of Kwara State Polytechnic Digital Library. International Journal of Advanced Research in Computer Science. Volume 4, No. 2, January-February, Pp 65-69. Available Online at www.ijarcs.info.

[7] Raji, A. K et al (2012). Wireless Internet Access Use by Staff and Students at the Kwara State Polytechnic, Ilorin-Nigeria. International Journal of Advanced Research in Computer Science. Volume 3, No. 4, July-August, Pp 279-282. Available Online at www.ijarcs.info.

[8] The JADE Project Home Page, available at http://www.jade.tilab.com. Retrieved on 17 March, 2011.

[9] Cougaar Software Inc. "An Intelligent Agent Technology Company, understanding the Technology series" http://www.coogaarsoftware.com Retrieved on 23/2/2014

[10] R. Stuart and N. Peter. "Artificial Intelligence: A Modern Approach", Prentice Hall: Ney York, 1995.

[11] P. Maes."Intelligent Software: Program that can act independently will ease the burdens that computer put on people". A Journal of Scientific American, 273(3), 84-86, 1995.

[12] C. E. Richards Jnr. "Intelligent agent-based management of heterogeneous networks for the Army enterprise". Naval postgraduate school, Monterey: California.

[13] M. A. Kianifar, D. R Naji and M. V. Malakooti, Multi-Agent and Clustering Based Wireless Sensor Network. Research Journal of Fishery and Hydrobiology, 2015, Vol. 10, Issue 9, Pp 240-246.

[14] O. Dagdeviren, I. Korkmaz, F. Tekbacak and K. Erciyes, A Survey of Agent Technologies for Wireless Sensor Networks. IETE Technical Review, Vol. 27, 2010, Pp 1-17.

[15] M. Bendjima and M. Feham, Intelligent Wireless Sensor Network Management based on a Multi-agent System. International Journal of Computer Science and Telecommunication, Vol. 3, Issue 2, February 2012. 